EPiC Series in Engineering
Volume 3, 2018, Pages 936-940
HIC 2018. 13th International
Conference on Hydroinformatics

\title{
Approach to mitigation of territory inundation with help of flood control by small water reservoirs.
}

\author{
Ilinich V.V. ${ }^{1}$, Perminov A.V. ${ }^{1}$, Rukhovich O.V. ${ }^{2}$, Naumova A.A. ${ }^{1}$ \\ ${ }^{1}$ Russian state agrarian university - Moscow agricultural academy \\ ${ }^{2}$ Pryanishnikov All-Russian Institute of Agrochemistry \\ vilinitchegmail.com
}

\begin{abstract}
.
The research dedicated to modeling of flood mitigation on the river basin with help of simulation of flood control by virtual small water reservoirs located in different places of the river system. Such problem decided with help of modeling of flood hydrograph and its routing through water reservoir on the base GIS. Reducing the degree of flooding should occur due to the limited hydraulic flow capacity of the water flow by dam spillways without flood control by people. The offered model is represented on the example of concrete river basin. Results have showed relevance of the model for flood mitigation on the river basin.
\end{abstract}

\section{Introduction}

Rainwater floods are especially unexpected for flood control of reservoirs located on river systems, where the concentration of maximum flows is small. The main objective of the study is to assess the possibility of mitigating floods by placing new small water reservoirs (ponds) in river system with dams. Reducing the degree of flooding should occur due to the limited hydraulic flow capacity of the water flow by hydraulic dam structures.

This approach requires the mathematical modeling of the following components: the surface of the river basin with its main physical and geographical characteristics using a GIS system;

- hydrological modeling of rain water runoff to the virtual water reservoir; - modeling of flood water routing through spillway construction of dam.

Modeling should provide:

- the possibility of obtaining the hydrographic characteristics of virtual reservoirs with their various locations on the rivers of the entire river basin on the base of GIS;

- the possibility of analyzing flood control by water reservoirs located in different places of river system and having dams with different sizes of spillways. 


\section{Methods and materials}

As a research object, the catchment of the Tyrlyand water reservoir, located in the Republic of Bashkiria of the Russian Federation on the inflow to the Belaya River was chosen. The catchment area has large slopes and, correspondingly, a rapid concentration of maximum runoff. In August 1994 the dam of Tyrlyand water reservoir has been distracted due to catastrophic rain flood. Now there is necessary of mitigation of flood on catchment of the water reservoir. The problem is offered to decide with help of small water reservoirs, which must decrease maximum water discharges to the Tyrlyand water reservoir. Consequently, modelling of flood control used on the example of virtual small water reservoir.

Surface of catchment represented with help of Geoinformation system Golden Software Surfer (far GIS). The GIS is currently the industry standard for constructing graphic images of the Earth's surface. The advantage of the program are the interpolation algorithms inherent in it, which, with the highest quality, allow the creation of digital surface models from spatially unevenly distributed data. The maps obtained with help of GIS represented on Figure 1figures 1 and Figure 2.

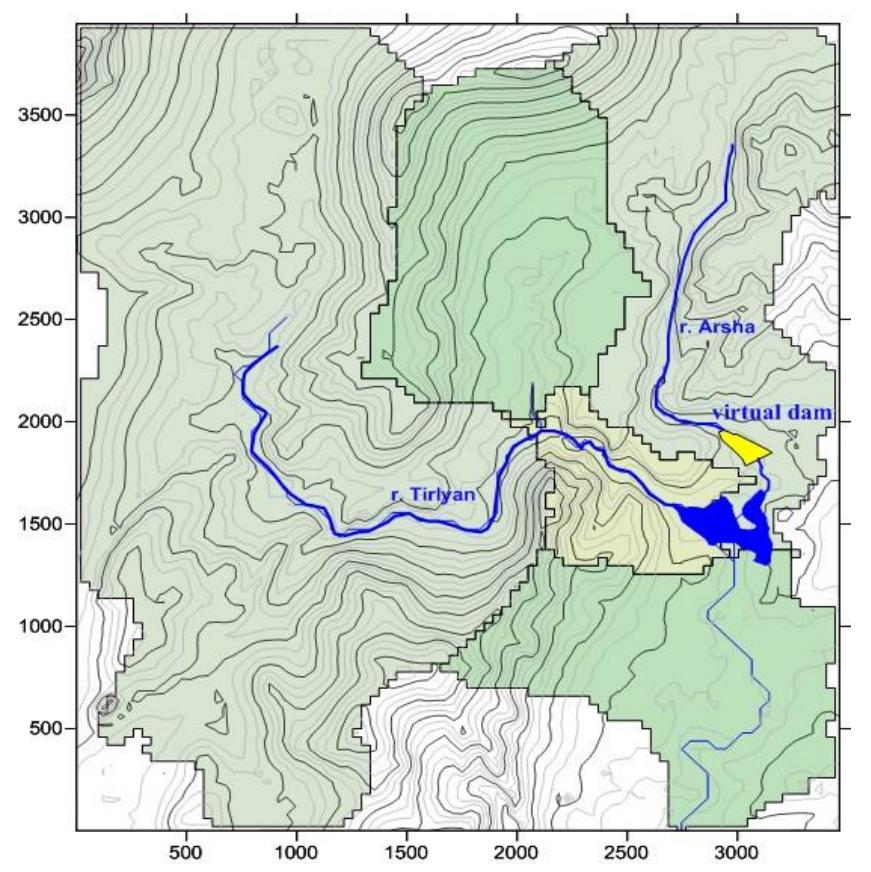

Figure 1: Watershed map for determination of hydrographic characteristics

A map was created with help of GIS (Golden Software Surfer v13). It allows determine hydrographic characteristics of any catchment area within the presented river system with needed scale. For example, there is possibility to determine: square of the concreate catchment and its average slope, length and slope of the river, which are needed for calculation maximum water discharge according to hydrological model. 


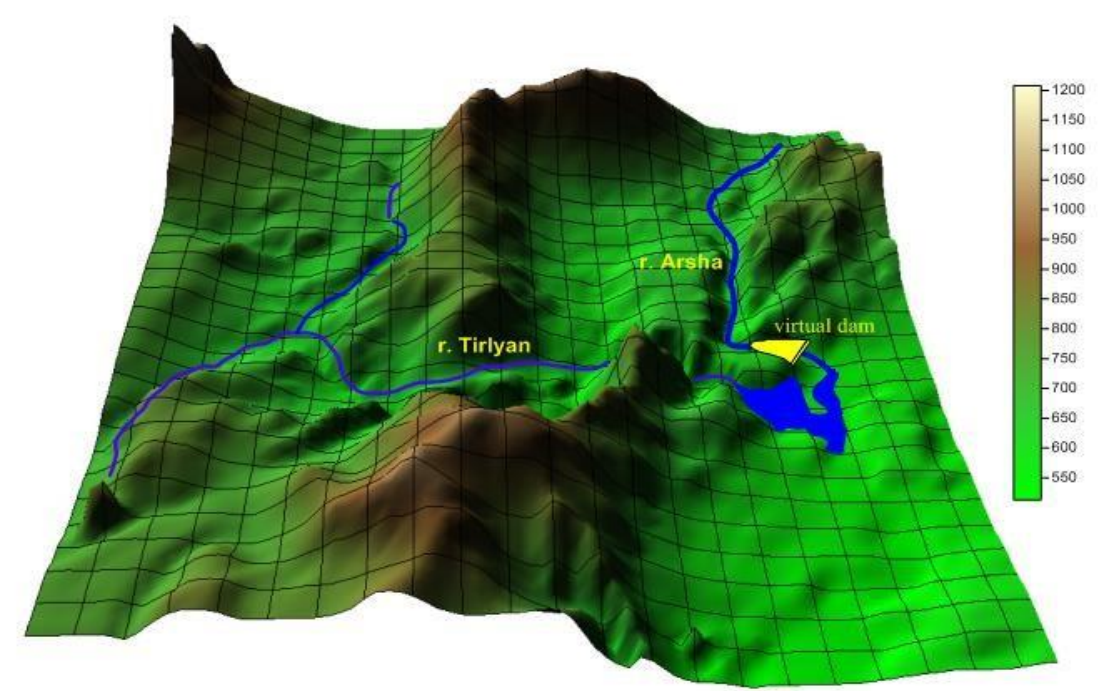

Figure 2: Surface of river system $3 \mathrm{~d}$

As a hydrological model of the maximum rain runoff, a formula (1) was used in respect to maximum discharge $\left(Q_{P}\right)$. The formula is recommended by the regulatory documents [1] of the Russian Federation for projects of hydro technical constructions on small rivers.

$$
Q_{P}=A_{P} \varphi H_{1 \%} \delta \lambda_{P} F
$$

Here: $H_{1 \%}$ - maximum daily depth of precipitation of probability $1 \% ; \varphi$ - special parameter of maximum runoff; $A_{P}$ - the modulus of maximum discharge of probability $1 \%$, expressed in fractions of the $\varphi H_{1 \%} ; \delta$ - coefficient, which takes into account the influence of lakes on the river basins; $\lambda_{P}$ - coefficient which allows transform the calculated maximum discharge for other normative probability ( $P=0,1 \% ; P=3 \% ; P=5 \% ; P=10 \%), F$ - river basin square.

The value $H_{1 \%}$ has been determined according to data observation of nearest meteorological station and traditional probabilistic model $[1,2]$. The value of $\varphi$ is determined by special applications $[1,2]$ depending on the number of hydrographic characteristics of river and catchment, including hydromorphological riverbed characteristic $\Phi_{P}$ by iteration in respect to value of parameter $\varphi$ :

$$
\Phi_{P}=\frac{1000 L}{m_{P} I_{P}^{m} F^{0,25}\left(\varphi H_{1 \%}\right)^{0,25}}
$$

Here: $m_{P}$ - hydraulic parameter of riverbed depended on average depth and broad of the river; $L$ -length of river bed, $\mathrm{km} ; I_{P}$ - river slope, $\%$ oo $m$ - special parameter of riverbed depended on region of river; $F$ - river basin square.

A hydrograph form of escapage discharge through overflow spillway depends on form and sizes of dam spillway and place of its location on the river, that can be changed. Accordingly, the bathygraphical 
curve of water reservoir (dependence between water storages and water level $-V=f(Z)$ can be changed with help of GIS. Spillway represented by tube since this variant supposes not expensive dam.

The runoff hydrographs to water reservoir are transformed to hydrographs of discharges of drafts from storage through overflow spillway with help calculations of method of approximate integration of Potapov $[2,3]$. The method uses next equations:

$$
\begin{aligned}
& Q d t-q d t=d V \\
& q=\mu \omega \sqrt{2 g} \cdot Z_{0}^{0,5}
\end{aligned}
$$

Here: $Q$ - water discharges of runoff to water reservoir; $q$ - discharges of drafts from storage of the reservoir; $d V$ - change of water reservoir storage for the time $d t ; \mu$-coefficient of spillway discharge; $\omega$-total size of spillway tubes; $g$-acceleration of gravity; $Z_{0}$ - water height over crest of spillway.

\section{Result and discussion}

The runoff hydrograph to water reservoir is represented on the Figure 3 by blue color. The hydrograph was obtained with help of calculation (formula 1) of maximum discharge $Q_{1 \%}=61,5 \mathrm{~m}^{3} / \mathrm{s}$ according to parameters determined on the base of GIS and according to requirements of documents [1].

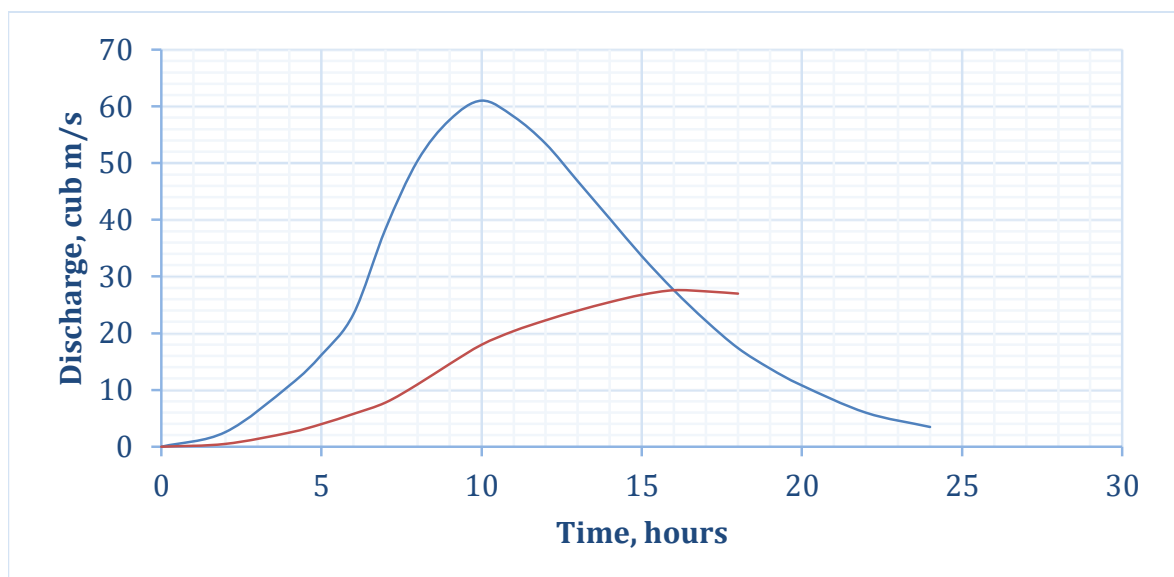

Figure 3: Graphs of runoff ( $\mathrm{m} 3 / \mathrm{s})$ to water reservoir and of discharges of drafts from water storage in respect to time (hours).

The graph of discharges of drafts from storage of the reservoir is represented on the Figure 3 by brown color until moment of maximum discharge $q_{\max }=29 \mathrm{~m}^{3} / \mathrm{s}$, which is much less $Q_{1 \%}=61,5 \mathrm{~m}^{3} / \mathrm{s}$. The graph was determined by deciding of system of equations $(3,4)$ and dependence between levels and storages of virtual water reservoir (Figure 4). The dependence was determined preliminary on the base of GIS in respect to place of virtual dam, which is showed on the (Figure 2) by yellow color. 


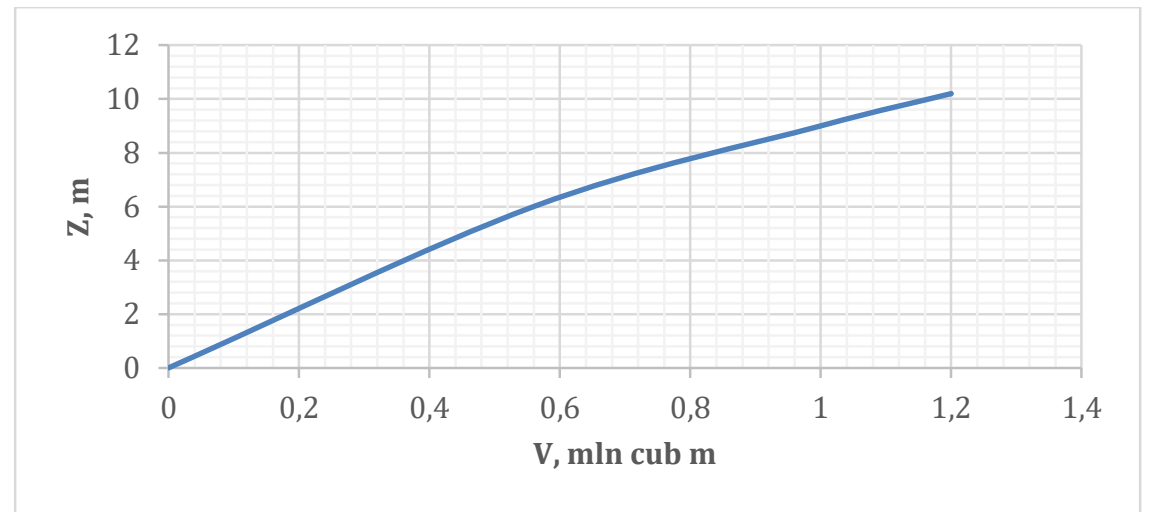

Figure 4: Dependence between levels and storages of virtual water reservoir

We can see on the (Figure 3) that maximum water discharge has been decreased significantly. So, we have mitigation of flood impact on the main water reservoir - Tyrlyand.

This is an example of the use of citations and references:

\section{Reference}

Determination of design hydrological performance (CП 33-101-2003), Moscow, 2003, P. 70 (Rus). Ovcharov E.E., Ilinitch V.V., Proschliakov I.V. and oth. Testbook "Hydrology and regulation of ranoff', Minsk, 2008, p 242.

Potapov M.V. Compositions. Vol. 3. Moscow, 1951, P. 479. (Rus). 